\title{
Plasma Phosphorylated-tau181 is a Predictor of Post-Stroke Cognitive Impairment: A Longitudinal Study
}

Li-Kai Huang

Shuang Ho Hospital

Shu-Ping Chao

Shuang Ho Hospital

Chaur-Jong Hu

Taipei Medical University

Yu-Chun Lo

Taipei Medical University

Yi-Chen Hsieh ( $\square$ ychsieh@tmu.edu.tw)

Taipei Medical University https://orcid.org/0000-0002-1863-287X

\section{Research}

Keywords: early-onset PSCl, delayed-onset PSCl, p-tau181, ischemic stroke, cognition

Posted Date: July 24th, 2021

DOI: https://doi.org/10.21203/rs.3.rs-726823/v1

License: (1) This work is licensed under a Creative Commons Attribution 4.0 International License. Read Full License 


\section{Abstract}

\section{Introduction}

Post-stroke cognitive impairment (PSCl) cannot be neglected because it drastically influences the daily life of patients and their families. However, there are no studies exploring the association between preclinical blood biomarkers of neurodegeneration including plasma amyloid- $\beta(A \beta)$, tau and brain-derived neurotrophic factor (BDNF) together with the risk of PSCl. The present longitudinal study was to investigate whether these blood biomarkers with imaging markers of cerebral small vessel disease can improve the prediction for PSCI. In addition, we also explored the association between blood biomarkers with the trajectories of PSCl.

\section{Methods}

Adult patients with first ever acute ischemic stroke were recruited, and the cognitive and functional abilities of these patients were evaluated. Furthermore, blood biomarkers of neurodegeneration including plasma $A \beta-40, A \beta-42$, total tau, phosphorylated tau 181 ( $p$ tau181), and BDNF levels and image markers of cerebral small vessel disease were measured. Each patient was followed up at 3 and 12 months at the outpatient department.

\section{Results}

Of 136 patients, 40 and 50 patients developed $\mathrm{PSCl}$ at 3 and 12 months after stroke, respectively. In functional trajectories, 27 patients did not have PSCl at 3 months but did at 12 months. By contrast, the PSCl status of 17 patients at 3 months was reversed at 12 months. Patients with high acute plasma p-tau181 had a significantly lower PSCI risk at 3 months (odds ratio [OR] $=0.62,95 \%$ confidence interval $[\mathrm{Cl}]=0.40-0.94, \mathrm{p}=0.0243)$ and 12 months $(\mathrm{OR}=0.69,95 \% \mathrm{Cl}=0.47-0.99, \mathrm{p}=0.0443)$ after adjustment for covariates and image biomarkers. Discrimination and reclassification statistics indicated that the p-tau181 level can improve discrimination ability for PSCl at 3 and 12 months, respectively. Additionally, the plasma p-tau181 level was the highest in subjects without PSCI followed by those with delayed-onset PSCI and early-onset PSCI with reversal, whereas the lowest plasma p-tau181 level was found among those with persistent PSCl, showing a significant trend test $(p=0.0081)$.

\section{Conclusions}

Plasma p-tau181 is a potential biomarker for predicting early- and delayed-onset PSCl. Future studies should incorporate plasma ptau181 as indicator for timely cognitive intervention in the follow-up of patients with stroke.

\section{Introduction}

Cognition decline after stroke is not rare. Clinical course of post-stroke cognitive impairment (PSCl) is not a unitary syndrome, but varies from individual to individual (1). Cognitive impairment assessment is often performed at 3-6 months after acute stroke to provide sufficient time for delirium resolution and neurological stability. Notably, stroke patients free of early-onset PSCI (3-6 months after stroke) are still at risk of delayed-onset PSCI ( $>6$ months after stroke), which suggests an underlying pathological process beyond 3 months after stoke (2). Many risk factors for PSCI have been proposed based on observational studies, including age, sex, educational attainment, stroke severity, stroke histories, and cardiovascular risk factors-particularly diabetes mellitus and hypertension (3). Brain image risk factors include white matter hyperintensities and gray matter and hippocampal volumes loss (4-6). However, there is still a lack of precise blood biomarkers for predicting PSCl.

Accumulation of amyloid beta $(A B)$ peptides and phosphorylated tau (p-tau) in brain are both key pathological feature of Alzheimer's disease $(7,8)$. Several previous studies implicated plasma $A \beta 40$ and $A \beta 42$ level was associated with cognitive decline among older adults and stroke patients $(9,10)$. Some cohorts found that plasma tau phosphorylated at threonine 181 ( $p$-tau181) was associated with cognitive decline (11). In addition, brain-derived neurotrophic factor (BDNF) is an important neurotrophin in the adult brain, which can help the brain to repair (12). Previous study further found that serum BDNF levels are decreased in the acute phase of stroke, and lower circulating concentrations of BDNF protein are associated with poor long-term functional outcomes (13).

Since these key peptides and proteins play important roles in cognitive performance, and there are few studies to examine the plasma levels of $A \beta 42$, tau, BDNF, and p-tau181 in patients after stroke through longitudinal follow-up, the purpose of this study was to investigate whether these blood with imaging markers-can improve the prediction for PSCl. In addition, the association between blood biomarkers with the trajectories of PSCI was also examined. 


\section{Methods}

\section{Study participants}

Patients aged $\geq 20$ years who were admitted to Shuang-Ho Hospital, Taipei Medical University within 7 days of acute ischemic stroke were screened for enrollment between 2015 and 2018. Patients with known premorbid cognitive impairment or neurodegenerative diseases that have impaired daily activities were excluded. In order to focus on the cognitive trajectory after stroke, we excluded the major cognitive impairment of stroke: large-scale infarcts that cause immediate consciousness impairment; strategic infarcts involving the thalamus, hippocampus, or medial frontal cortex; and severe language or physical disabilities that hinder neuropsychological testing. Each patient was evaluated in the hospital within 7 days of stroke and followed up in the outpatient clinic at 3 and 12 months. The Institutional Review Board of Taipei Medical University approved the study. Written informed consent was obtained from all patients or their legal guardians.

\section{Data collection}

Brain magnetic resonance images were obtained once at admission, including T1- and T2-weighted images, T2 fluid-attenuated inversion recovery (T2 FLAIR) images, diffusion-weighted images (DWI), apparent diffusion coefficient (ADC) maps, T2 star-weighted angiography (SWAN) and time-of- flight magnetic resonance angiograms. Acute ischemic brain infarction was confirmed with hyperintensity on DWI with corresponding ADC maps. Visual ratings of white matter hyperintensities $(\mathrm{WMH})$ were performed by an investigator who was blinded to the clinical details by applying Fazekas rating scale (14). Microbleeds were rated as round or ovalshaped dark blooming signals $(2-10 \mathrm{~mm}$ in diameter) using the Microbleeds Anatomical Rating Scale (MARS) on the SWAN image and were classified into deep, lobar, and infratentorial categories (15). Stroke severity was assessed using the National Institute of Health Stroke Scale (NIHSS) at admission. The stroke etiological subtype was classified according to The Trial of ORG 10172 in Acute Stroke Treatment (TOAST) classification by an experienced neurologist who was unware of outcomes of patients. Two neuropsychologists conducted cognitive function assessments using the Taiwanese version of the Montreal Cognitive Assessment (MoCA) screening instrument(16) and the Clinical Dementia Rating (CDR) global score, Sum of Boxes (CDR-SB; range: 0-18). MoCA showed a low ceiling effect with high sensitivity and specificity when used for assessing cognitive impairment after stroke (17). The CDR-SB comprises six cognitive and functional domains (memory, orientation, judgment and problem solving, community affairs, home and hobbies, and personal care), which yield additional information, particularly regarding mild impairment (18). In this study, we defined PSCl as a CDR$\mathrm{SB}>0$ when the patient presented with functional impairment after stroke in either one or more of the six domains. In addition, we further classified patients based on the 3-month and 12-month CDR-SB assessments to understand the trajectory of PSCl after stroke. Persistent non-PSCl is defined as 3-month and 12-month CDR-SB=0 $(n=69)$, delayed-onset PSCI is CDR-SB $=0$ at 3 months while CDR$S B \geq 0.5$ at 12 months $(n=27)$, early PSCl with reversal is 3 -month CDR-SB $\geq 0.5$ and 12 -month CDR-SB $=0(n=17)$, and persistent $P S C l$ is $C D R-S B \geq 0.5$ at 3 months and 12 months $(n=23)$.

\section{Measurement of plasma biomarkers}

Two 10-mL non-fasting venous blood were collected within 7 days of stroke onset. The blood samples were centrifuged at 1,500 $\times \mathrm{g}$ for 15 min and stored at $-80^{\circ} \mathrm{C}$. Plasma $A \beta 40, A \beta 42$, total tau, and $p$-tau181 were analyzed using immunomagnetic reduction (IMR) assays manufactured by MagQu Co. Ltd. (New Protein Analysis Taipei City, Taiwan). Technical details of IMR assays have been described in previous studies $(10,19)$. BDNF was quantified through enzyme-linked immunosorbent assay by using cytokine detection kits (DY248; R\&D Systems, Minneapolis, MN, USA) according to the manufacturer's protocol. Absorbance at $450 \mathrm{~nm}$ was measured with a SpectraMax microplate reader (Molecular Devices, San Jose, CA, USA). All samples were analyzed in duplicate.

\section{Statistical analysis}

Continuous variables are presented as mean and standard deviation, and data with non-normal distribution are expressed as medians with interquartile ranges. Categorical variables are presented in terms of frequency with percentage. Univariate logistic regression was used to estimate the odds ratios (ORs) of $\mathrm{PSCl}$ at 3 and 12 months based on clinical characteristics and laboratory data. The identified important covariates with borderline significant in the univariate analysis were then verified in the multivariate logistic model by using automatic forward selection methods. Receiver operating characteristic (ROC) analysis was conducted to estimate the performance of plasma biomarkers combined important covariates for differentiating PSCl risk at 3 and 12 months. In addition, the net reclassification index (NRI) and integrated discrimination improvement (IDI) were computed to evaluate the incremental prognostic value of plasma 
biomarkers beyond conventional risk factors as well as image biomarkers. All statistical analyses were performed using SAS (version 9.4, Cary, North Carolina). A two-tailed $p$ value $<0.05$ was considered statistically significant.

\section{Results}

Study participants

All 173 participants completed initial clinical and neuropsychological examinations as well as plasma biomarker assays and a brain MRI scan within 7 days after stroke. No patient died during the follow-up time of 1 year. Attrition was due to loss to follow-up in 37 patients at 3 months. Data from 136 patients was processed in the final analysis. At 3 months after stroke, 40 patients met criteria for $\mathrm{PSCl}$ according to CDR-SB > 0, whereas at 12 months after stroke, 50 patients had $\mathrm{PSCl}$ (Figure 1).

\section{Characteristics of study subjects}

Demographic data, brain MRI visual rating scores and plasma biomarkers are summarized in Table 1. Dividing into two groups according to whether positive of PSCl at 3 months after stroke, the mean ages of patients with and without PSCl were $61.43 \pm 12.57$ and $57.73 \pm 12.66$ years, respectively. A total of $40 \% \mathrm{PSCl}$ patients have an education level of $>9$ years, which is significantly lower than that of non-PSCl patients. A remarkably high frequency of hypertension was observed among patients with $\mathrm{PSCl}$ compared with those without PSCl. Most patients had mild stroke severity, and median NIHSS scores within 7 days for patients with and without PSCI were 4 and 3, respectively. Periventricular white matter Fazeka scale was significantly different between two groups. MoCA scores at 3 and 12 months were significantly lower in patients with PSCI than in those without PSCl. Furthermore, the plasma p-tau181 level in patients with PSCI $(3.19 \pm 1.77 \mathrm{pg} / \mathrm{mL})$ was significantly lower than in those without PSCl $(4.16 \pm 2.18 \mathrm{pg} / \mathrm{mL})$.

\section{Univariate and multivariate regression analyses of PSCl risk}

Table 2 presents the results of univariate and multivariate logistic regression analyses for patients with and without PSCI at both 3 and 12 months, respectively. For PSCl at 3 months, education level, plasma p-tau181 level, periventricular white matter Fazeka scale, and MARS lobar score were significant factors in the univariate model. These identified important covariates together with hypertension were then verified in then multivariate analysis. After forward selection, education level, hypertension and plasma p-tau181 level were significantly independent factors of PSCl, showing the patients having an increased p-tau181 level had a significantly lower risk of PSCI at 3 months $(O R=0.62,95 \%$ confidence interval $[C l]=0.40-0.94, p=0.0243)$. Similar findings were found when the patients followed up to 12 months. For patients with increment of $p$-tau181 level had a 0.69 -fold risk of $\mathrm{PSCl}$ at 12 months $(95 \% \mathrm{Cl}=0.47-0.99, \mathrm{p}=$ 0.0443). However, plasma tau, $A \beta 42, A \beta 40$, and BDNF were not predictors of $\mathrm{PSCl}$ at 3 or 12 months.

\section{Predictive accuracy of p-tau181 for assessing PSCI}

To examine the effect of p-tau181 on PSCl at 3 and 12 months in addition to conventional risk factors, discrimination and reclassification statistics were calculated. Figure 2 illustrates the area under the curve (AUC) of the model based only on conventional risk factors was $0.7632(95 \% \mathrm{Cl}=0.6520-0.8744)$, but it slightly increased to $0.7655(95 \% \mathrm{Cl}=0.6549-0.8761)$ when image biomarkers were added. After integrating plasma p-tau181 level, the performance has been greatly improved, which achieved to good discrimination ability (AUC $=0.8067 ; 95 \% \mathrm{Cl}=0.7066-0.9067$ ). According to the NRI and IDI indexes, adding the p-tau181 level to the model containing conventional risk factors and image biomarkers significantly improves the measure of reclassification and discrimination for $\mathrm{PSCl}$ at 3 and 12 months (Table 3).

\section{Association between plasma biomarkers and different persistent cognitive impairment status}

Plasma biomarkers were analyzed according to the trajectory of cognitive impairment status defined by the CDR-SB at 3 and 12 months. Table 4 presents the levels of plasma tau, $A \beta 42, A \beta 40, A \beta 42 / 40$ ratio, $p$-tau181, and BDNF among the four subgroups. The results indicated that only plasma p-tau181 level differed among the four groups, with the highest level in the persistent non-PSCl group $(4.40 \pm 1.77 \mathrm{pg} / \mathrm{mL})$ followed by the delayed-onset PSCl $(3.65 \pm 1.41 \mathrm{pg} / \mathrm{mL})$, early PSCl with reversal $(3.36 \pm 1.38 \mathrm{pg} / \mathrm{mL}) \mathrm{groups}$, and the lowest level was in the persistent PSCl group $(3.12 \pm 0.78 \mathrm{pg} / \mathrm{mL})$, showing a significant trend test $(\mathrm{p}=0.0081)$.

\section{Discussion}


The present study investigated 136 patients with acute ischemic stroke and followed them up for consequential cognitive function trajectory for 1 year. The results demonstrated that a high plasma p-tau181 level in the acute post-stroke stage is related to a low PSCI risk at $3(\mathrm{OR}=0.62,95 \% \mathrm{Cl}=0.40-0.94, \mathrm{p}=0.0243)$ and $12(\mathrm{OR}=0.69,95 \% \mathrm{Cl}=0.47-0.99, \mathrm{p}=0.0443)$ months. Integrating $\mathrm{p}$-tau181 to the model containing conventional risk factors (age, education, hypertension, diabetes mellitus, and NIHSS score at $\leq 7$ days) and image biomarker significantly improves prediction.

Cognitive improvement after stroke often occurs within 6 months, and early recognition of $\mathrm{PSCl}$ is necessary for assessing the need for rehabilitation (20). In the case of cerebral ischemia, hyperphosphorylated tau protein may play a protective role by promoting $\beta$-catenin and other proteins to inhibit cell apoptosis, suggesting that neurons survive apoptotic attacks and achieve self-repair (21). Phosphorylation of tau results in reduced binding to microtubules and potentially enhances plasticity, as observed during brain development, which is also important in neural repair after stroke (22). In Alzheimer disease (AD), plasma p-tau181 is a prognostic and confirmatory biomarker (23). Hyperphosphorylated tau protein forms paired helical filaments and progressively aggregates to form the main component of neurofibrillary tangles in AD pathology (24). However, unlike in AD pathology, neurofibrillary tangles are rarely seen in the brain after stroke. Studies of cerebrospinal fluid (CSF) samples from patients with acute stroke showed that CSF p-tau did not increase persistently, whereas CSF total tau increased and returned to normal levels at 3-5 months after stroke, suggesting different pathogenic processes from AD (25-27). Therefore, the diagnostic criteria for vascular cognitive disorders from the International Society of Vascular Behavioral and Cognitive Disorders statement suggest excluding CSF p-tau when diagnosing vascular cognitive impairment in research (28), whereas a persistent increase in CSF p-tau is considered a defining biomarker of AD in the National Institute on AgingAlzheimer's Association Research Framework (29). In addition, plasma p-tau181 predicted PSCI in a dose-dependent manner in our longitudinal cohort study, and the p-tau181 level was the highest in the persistent non-PSCl group and the lowest in the persistent PSCI group. A protective role for tau phosphorylation at threonine 181 could facilitate its binding to exosomes and the release of excess tau (30). Further studies are warranted to understand the mechanism underlying this finding.

Previous studies have revealed that plasma $A \beta 42 / 40$ ratios are surrogate biomarkers of cortical $A \beta$ deposition (31). High plasma concentrations of $A \beta 40$, especially when combined with low concentrations of $A \beta 42$, indicate an increased dementia risk (32). In our study, $A \beta 42, A \beta 40$, and $A \beta 42 / 40$ ratio were not different between patients with and without $P S C l$, which suggests the involvement of additional processes other than amyloid pathology. In addition, BDNF was found to be an indicator of long-term functional outcomes after ischemic stroke, although the additional predictive value of BNDF was modest according to clinical data (13). Our data showed that there was no significant difference in circulating BDNF levels regardless of whether the patient had PSCl or not, which may be due to its limited impact on cognitive outcomes.

CDR-SB was adopted to define PSCl in our study. Given the diverse clinical presentation of PSCl, not only memory but also other cognitive domains should be evaluated (33). The global CDR is weighted more on memory dysfunction, whereas CDR-SB is weighted equally for all domains (34). In addition, CDR-SB has been considered as an effective and reliable assessment method, which combines two sets of questions, one set is for the insider and the other is for the subject. This implies the use of CDR-SB to define the PSCl has a clinically significant impact in the follow-up after stroke. In our study, none of the patients had dementia before stroke. However, the prevalence of $\mathrm{PSCl}$ at 3 and 12 months after stroke was $29.4 \%$ and $36.8 \%$, respectively, during the longitudinal follow-up. The reported prevalence varied among previous studies depending on divergent estimates of $\mathrm{PSCl}$ according to the population under study and the methods of defining PSCl, suggesting a need for diagnosis criteria consensus $(35,36)$.

Notably, in our cohort, 27 patients without PSCl at 3 months developed PSCl at 12 months after stroke (late PSCl: 19.9\%), and 17 patients reversed from PSCl at 3 months to Non-PSCl at 12 months (reversal: $42.5 \%$ ). Our findings further revealed that a dosedependent trend of plasma p-tau181 level existed among patients with various persistent cognitive impairment statuses, with the highest level in the non-PSCl group followed by the early PSCl with reversal and delayed-onset PSCl groups; the lowest level was in the persistent PSCI group, which implicated the protective effect on longitudinal cognitive function after a minor ischemic stroke.

The present study has several limitations. First, there was no formal test conducted for measuring baseline cognitive function before stroke in our participants. However, patients with known cognitive impairment or neurodegeneration that impaired daily activities before stroke were excluded based on their medical histories at the screening phase. Additionally, this study adopted the CDR-SB to define PSCI in order to distinguish functional changes after stroke since we relied on informant-based evidence rather than performance-based tests. Second, the severity of stroke in the patients in this study is relatively small and mainly involves small vessel diseases which might influence the generalizability of the findings to large brain infarction or intracranial hemorrhage. Future studies will be needed to elucidate the natural course of other types of brain insults. Third, in our study, no further AD diagnosis was performed; however, 
previous findings indicated that after ischemia with reperfusion in the brain, secondary neurodegeneration of AD type may occur (37). Further longitudinal studies regarding biomarkers are needed to distinguish PSCI and AD processes.

In conclusion, $\mathrm{PSCl}$ is not uncommon in the population with minor stroke. Using plasma p-tau181 as a surrogate biomarker for predicting early- and delayed-onset PSCI is helpful in interventional studies and clinical follow-up.

\section{List Of Abbreviations}

PSCl: post-stroke cognitive impairment; $A \beta$ : amyloid- $\beta$; BDNF: brain-derived neurotrophic factor; p-tau181: phosphorylated tau 181; OR: odds ratio; Cl: confidence interval; T2 FLAIR : T2 fluid-attenuated inversion recovery ; DWI: diffusion-weighted images; ADC: apparent diffusion coefficient; WMH: white matter hyperintensities; MARS: Microbleeds Anatomical Rating Scale; NIHSS: National Institute of Health Stroke Scale; TOAST: The Trial of ORG 10172 in Acute Stroke Treatment; MoCA: Montreal Cognitive Assessment; CDR: Clinical Dementia Rating; CDR-SB: Clinical Dementia Rating global score, Sum of Boxes; IMR: immunomagnetic reduction; ROC: Receiver operating characteristic; NRI: net reclassification index; IDI: integrated discrimination improvement; AUC: area under the curve; AD: Alzheimer disease; CSF: cerebrospinal fluid.

\section{Declarations}

\section{Ethics approval and consent to participate}

This study was approved by the Institutional Review Board of Taipei Medical University. Written informed consent was obtained from all patients or their legal guardians.

\section{Consent for publication}

Not applicable.

\section{Availability of data and materials}

The datasets used and/or analyzed during the current study are available from the corresponding author on reasonable request.

\section{Competing interests}

The authors declare that they have no conflict of interest.

\section{Funding}

This study was supported by Academia Sinica Stroke Biosignature Project (BM10701010021), Taiwan Ministry of Science and Technology (MOST) Clinical Trial Consortium for Stroke (MOST 107-2321-B-039-004, 106-2314-B-038-001, and 107-2314-B-038-050).

\section{Authors' Contributions}

LKH wrote the manuscript with support from $\mathrm{YCH}$. YCH verified the analytical methods. CJH conceived the study and were in charge of overall direction and planning. YCL aided in interpreting the results and worked on the manuscript. All authors discussed the results and contributed to the final manuscript.

\section{Acknowledgments}

This manuscript was edited by Wallace Academic Editing.

\section{References}

1. Patel MD, Coshall C, Rudd AG, Wolfe CD. Cognitive impairment after stroke: clinical determinants and its associations with longterm stroke outcomes. Journal of the American Geriatrics Society. 2002;50(4):700-6. 
2. Wagle J, Farner L, Flekkoy K, Bruun Wyller T, Sandvik L, Fure B, et al. Early post-stroke cognition in stroke rehabilitation patients predicts functional outcome at 13 months. Dement Geriatr Cogn Disord. 2011;31(5):379-87.

3. Sun JH, Tan L, Yu JT. Post-stroke cognitive impairment: epidemiology, mechanisms and management. Ann Transl Med. 2014;2(8):80.

4. Dichgans M, Leys D. Vascular Cognitive Impairment. Circ Res. 2017;120(3):573-91.

5. Ding MY, Xu Y, Wang YZ, Li PX, Mao YT, Yu JT, et al. Predictors of Cognitive Impairment After Stroke: A Prospective Stroke Cohort Study. J Alzheimers Dis. 2019;71(4):1139-51.

6. Mok VC, Lam BY, Wong A, Ko H, Markus HS, Wong LK. Early-onset and delayed-onset poststroke dementia - revisiting the mechanisms. Nat Rev Neurol. 2017;13(3):148-59.

7. Jack CR, Jr., Bennett DA, Blennow K, Carrillo MC, Dunn B, Haeberlein SB, et al. NIA-AA Research Framework: Toward a biological definition of Alzheimer's disease. Alzheimers Dement. 2018;14(4):535-62.

8. Drummond E, Pires G, MacMurray C, Askenazi M, Nayak S, Bourdon M, et al. Phosphorylated tau interactome in the human Alzheimer's disease brain. Brain. 2020;143(9):2803-17.

9. Giudici KV, de Souto Barreto P, Guyonnet S, Li Y, Bateman RJ, Vellas B. Assessment of Plasma Amyloid- $\beta 42 / 40$ and Cognitive Decline Among Community-Dwelling Older Adults. JAMA Netw Open. 2020;3(12):e2028634.

10. Tang S-C, Yang K-C, Chen C-H, Yang S-Y, Chiu M-J, Wu C-C, et al. Plasma $\beta$-amyloids and tau proteins in patients with vascular cognitive impairment. Neuromolecular medicine. 2018;20(4):498-503.

11. Karikari TK, Pascoal TA, Ashton NJ, Janelidze S, Benedet AL, Rodriguez JL, et al. Blood phosphorylated tau 181 as a biomarker for Alzheimer's disease: a diagnostic performance and prediction modelling study using data from four prospective cohorts. Lancet Neurol. 2020;19(5):422-33.

12. Liu W, Wang X, O'Connor M, Wang G, Han F. Brain-Derived Neurotrophic Factor and Its Potential Therapeutic Role in Stroke Comorbidities. Neural Plast. 2020;2020:1969482.

13. Stanne TM, Åberg ND, Nilsson S, Jood K, Blomstrand C, Andreasson U, et al. Low Circulating Acute Brain-Derived Neurotrophic Factor Levels Are Associated With Poor Long-Term Functional Outcome After Ischemic Stroke. Stroke. 2016;47(7):1943-5.

14. Fazekas F, Chawluk JB, Alavi A, Hurtig HI, Zimmerman RA. MR signal abnormalities at $1.5 \mathrm{~T}$ in Alzheimer's dementia and normal aging. AJR Am J Roentgenol. 1987;149(2):351-6.

15. Gregoire SM, Chaudhary UJ, Brown MM, Yousry TA, Kallis C, Jäger HR, et al. The Microbleed Anatomical Rating Scale (MARS): reliability of a tool to map brain microbleeds. Neurology. 2009;73(21):1759-66.

16. Tsai CF, Lee WJ, Wang SJ, Shia BC, Nasreddine Z, Fuh JL. Psychometrics of the Montreal Cognitive Assessment (MoCA) and its subscales: validation of the Taiwanese version of the MoCA and an item response theory analysis. Int Psychogeriatr. 2012;24(4):651-8.

17. Pendlebury ST, Mariz J, Bull L, Mehta Z, Rothwell PM. MoCA, ACE-R, and MMSE versus the National Institute of Neurological Disorders and Stroke-Canadian Stroke Network vascular cognitive impairment harmonization standards neuropsychological battery after tia and stroke. Stroke. 2012;43(2):464-9.

18. Lynch CA, Walsh C, Blanco A, Moran M, Coen RF, Walsh JB, et al. The clinical dementia rating sum of box score in mild dementia. Dement Geriatr Cogn Disord. 2006;21(1):40-3.

19. Chi N-F, Chao S-P, Huang L-K, Chan L, Chen Y-R, Chiou H-Y, et al. Plasma amyloid beta and tau levels are predictors of post-stroke cognitive impairment: A longitudinal study. Frontiers in Neurology. 2019;10:715.

20. Turunen KE, Laari SP, Kauranen TV, Uimonen J, Mustanoja S, Tatlisumak T, et al. Domain-specific cognitive recovery after firstever stroke: a 2-year follow-up. Journal of the International Neuropsychological Society. 2018;24(2):117-27.

Page $7 / 14$ 
21. Wang HH, Li HL, Liu R, Zhang Y, Liao K, Wang Q, et al. Tau overexpression inhibits cell apoptosis with the mechanisms involving multiple viability-related factors. J Alzheimers Dis. 2010;21(1):167-79.

22. Morris M, Maeda S, Vossel K, Mucke L. The many faces of tau. Neuron. 2011;70(3):410-26.

23. Bateman RJ, Barthélemy NR, Horie K. Another step forward in blood-based diagnostics for Alzheimer's disease. Nature Medicine. 2020:1-2.

24. Pevalova M, Filipcik P, Novak M, Avila J, Iqbal K. Post-translational modifications of tau protein. Bratisl Lek Listy. 2006;107(910):346-53.

25. Hagberg G, Ihle-Hansen H, Fure B, Thommessen B, Ihle-Hansen H, Øksengård AR, et al. No evidence for amyloid pathology as a key mediator of neurodegeneration post-stroke-a seven-year follow-up study. BMC neurology. 2020;20:1-11.

26. Hesse C, Rosengren L, Andreasen N, Davidsson P, Vanderstichele H, Vanmechelen E, et al. Transient increase in total tau but not phospho-tau in human cerebrospinal fluid after acute stroke. Neuroscience letters. 2001;297(3):187-90.

27. Hjalmarsson C, Bjerke M, Andersson B, Blennow K, Zetterberg H, Åberg ND, et al. Neuronal and glia-related biomarkers in cerebrospinal fluid of patients with acute ischemic stroke. Journal of Central nervous system Disease. 2014;6:JCNSD. S13821.

28. Sachdev P, Kalaria R, O'Brien J, Skoog I, Alladi S, Black SE, et al. Diagnostic criteria for vascular cognitive disorders: a VASCOG statement. Alzheimer Dis Assoc Disord. 2014;28(3):206-18.

29. Albert MS, DeKosky ST, Dickson D, Dubois B, Feldman HH, Fox NC, et al. The diagnosis of mild cognitive impairment due to Alzheimer's disease: recommendations from the National Institute on Aging-Alzheimer's Association workgroups on diagnostic guidelines for Alzheimer's disease. Alzheimer's \& dementia : the journal of the Alzheimer's Association. 2011;7(3):270-9.

30. Avila J, León-Espinosa G, García E, García-Escudero V, Hernández F, DeFelipe J. Tau phosphorylation by GSK3 in different conditions. International Journal of Alzheimer's Disease. 2012;2012.

31. Fandos N, Pérez-Grijalba V, Pesini P, Olmos S, Bossa M, Villemagne VL, et al. Plasma amyloid $\beta 42 / 40$ ratios as biomarkers for amyloid $\beta$ cerebral deposition in cognitively normal individuals. Alzheimers Dement (Amst). 2017;8:179-87.

32. van Oijen M, Hofman A, Soares HD, Koudstaal PJ, Breteler MM. Plasma Abeta(1-40) and Abeta(1-42) and the risk of dementia: a prospective case-cohort study. Lancet Neurol. 2006;5(8):655-60.

33. Skrobot OA, Black SE, Chen C, DeCarli C, Erkinjuntti T, Ford GA, et al. Progress toward standardized diagnosis of vascular cognitive impairment: Guidelines from the Vascular Impairment of Cognition Classification Consensus Study. Alzheimer's \& Dementia. 2018;14(3):280-92.

34. Wyman-Chick KA, Scott B. Development of Clinical Dementia Rating Scale Cut-off Scores for Patients With Parkinson's Disease. Movement disorders clinical practice. 2015;2(3):243-8.

35. Abzhandadze T, Rafsten L, Lundgren Nilsson ÅC, Palstam A, Sunnerhagen KS. Very early MoCA can predict functional dependence at 3 months after stroke: A longitudinal, cohort study. Frontiers in neurology. 2019;10:1051.

36. del Ser T, Barba R, Morin MM, Domingo J, Cemillan C, Pondal M, et al. Evolution of cognitive impairment after stroke and risk factors for delayed progression. Stroke. 2005;36(12):2670-5.

37. Pluta R. The role of apolipoprotein $\mathrm{E}$ in the deposition of beta-amyloid peptide during ischemia-reperfusion brain injury. A model of early Alzheimer's disease. Ann N Y Acad Sci. 2000;903:324-34.

\section{Tables}

Table 1. Basic characteristics of study subjects with and without PSCl defined at 3 months after stroke 


\begin{tabular}{|c|c|c|c|c|c|}
\hline \multirow{2}{*}{$\begin{array}{l}\text { Variables } \\
\text { Demographics }\end{array}$} & \multicolumn{2}{|c|}{ With PSCI } & \multicolumn{2}{|c|}{ Without PSCI } & \multirow[t]{2}{*}{ P-value } \\
\hline & $\mathrm{N}=40$ & & $N=96$ & & \\
\hline AGE, y, mean(SD) & 61.43 & $(12.57)$ & 57.73 & $(12.66)$ & 0.1225 \\
\hline Male, n(\%) & 30 & $(75.00)$ & 67 & $(69.79)$ & 0.5406 \\
\hline $\mathrm{BMI}, \mathrm{kg} / \mathrm{m}^{2}$, median(IQR) & 25.71 & $(3.95)$ & 25.68 & $(4.14)$ & 0.2448 \\
\hline Education>9 years, $\mathrm{n}(\%)$ & 16 & $(40.00)$ & 58 & $(60.42)$ & 0.0294 \\
\hline Cigarette smoking, n(\%) & 25 & $(62.50)$ & 46 & $(48.42)$ & 0.1347 \\
\hline Alcohol drinking, $n(\%)$ & 4 & $(10.00)$ & 11 & $(11.58)$ & 0.7898 \\
\hline \multicolumn{6}{|l|}{ Medical history } \\
\hline Hypertension, n(\%) & 36 & $(90.00)$ & 72 & $(75.00)$ & 0.0487 \\
\hline Diabetes mellitus, n(\%) & 16 & $(40.00)$ & 32 & $(33.33)$ & 0.4585 \\
\hline Dyslipidemia, n(\%) & 31 & $(77.50)$ & 72 & $(75.00)$ & 0.7566 \\
\hline \multicolumn{6}{|l|}{ Clinical features } \\
\hline Fasting glucose, mg/dL, median(IQR) & 111.00 & $(30.00)$ & 110.00 & $(29.00)$ & 0.7986 \\
\hline Total cholesterol, mg/dL, median(IQR) & 203.00 & $(66.50)$ & 198.00 & $(62.00)$ & 0.6652 \\
\hline NIHSS $\leq 7$ days, score, median(IQR) & 4.00 & $(3.50)$ & 3.00 & $(3.00)$ & 0.5064 \\
\hline MoCA at 3 months, score, median(IQR) & 22.50 & $(6.50)$ & 26.00 & $(5.00)$ & $<0.0001$ \\
\hline MoCA at 12 months, score, median(IQR) & 23.00 & $(7.00)$ & 27.00 & $(5.00)$ & 0.0007 \\
\hline \multicolumn{6}{|l|}{ Plasma biomarkers } \\
\hline$A \beta 42, p g / m L$, median(IQR) & 15.54 & $(2.48)$ & 15.66 & $(3.18)$ & 0.5763 \\
\hline$A \beta 40, p g / m L$, median(IQR) & 49.45 & $(7.76)$ & 49.75 & $(7.22)$ & 0.6824 \\
\hline$A \beta 42 / 40$ ratio, $\%$, median(IQR) & 32.60 & $(10.47)$ & 34.56 & $(11.32)$ & 0.3166 \\
\hline Tau, pg/mL, median(IQR) & 18.87 & $(9.43)$ & 18.64 & $(13.71)$ & 0.4920 \\
\hline $\mathrm{p}$-tau181, pg/mL, mean(SD) & 3.19 & $(1.77)$ & 4.16 & $(2.18)$ & 0.0053 \\
\hline BDNF, pg/mL, median(IQR) & 732.43 & $(317.00)$ & 724.97 & $(387.01)$ & 0.7755 \\
\hline \multicolumn{6}{|l|}{ TOAST } \\
\hline Large artery atherosclerosis, $\mathrm{n}(\%)$ & 8 & $(20.00)$ & 17 & $(17.71)$ & 0.3289 \\
\hline Small vessel occlusion, n(\%) & 24 & $(60.00)$ & 61 & $(63.54)$ & \\
\hline Cardioembolism, n(\%) & 3 & $(7.50)$ & 10 & $(10.42)$ & \\
\hline Specific etiology, n(\%) & 3 & $(7.50)$ & 1 & $(1.04)$ & \\
\hline Undetermined etiology, n(\%) & 2 & $(5.00)$ & 7 & $(7.29)$ & \\
\hline \multicolumn{6}{|l|}{ Fazekas scale } \\
\hline \multirow[t]{4}{*}{ Periventricular white matter } & 4 & $(10.26)$ & 33 & $(34.38)$ & 0.0036 \\
\hline & 12 & $(30.77)$ & 34 & $(35.42)$ & \\
\hline & 6 & $(15.38)$ & 4 & $(4.17)$ & \\
\hline & 17 & $(43.59)$ & 25 & $(26.04)$ & \\
\hline Deep white matter lesion & 5 & $(12.82)$ & 27 & $(28.13)$ & 0.1803 \\
\hline
\end{tabular}




\begin{tabular}{|lllllll|}
\hline 1 & 17 & $(43.59)$ & 42 & $(43.75)$ & \\
\hline 2 & 9 & $(23.08)$ & 13 & $(13.54)$ & \\
\hline Mirobleed anatomical rating scale & 3 & 8 & $(20.51)$ & 14 & $(14.58)$ & \\
\hline Infratentorial score & & & & & \\
\hline & 0 & 29 & $(76.32)$ & 81 & $(84.38)$ & 0.2812 \\
\hline 1 & 7 & $(18.42)$ & 8 & $(8.33)$ & \\
\hline Deep score & $2-4$ & 2 & $(5.26)$ & 7 & $(7.29)$ & \\
\hline & $>4$ & 0 & $(0)$ & 0 & $(0)$ & \\
\hline 0 & 27 & $(71.05)$ & 76 & $(79.17)$ & 0.5389 \\
\hline 1 & 6 & $(15.79)$ & 10 & $(10.42)$ & \\
\hline $2-4$ & 4 & $(10.53)$ & 9 & $(9.38)$ & \\
\hline Lobar score & $>4$ & 1 & $(2.63)$ & 1 & $(1.04)$ & \\
\hline 0 & 25 & $(65.79)$ & 74 & $(77.08)$ & 0.0617 \\
\hline 1 & 3 & $(7.89)$ & 13 & $(13.54)$ & \\
\hline $2-4$ & 9 & $(23.68)$ & 7 & $(7.29)$ & \\
\hline$>4$ & 1 & $(2.63)$ & 2 & $(2.08)$ & \\
\hline & & & & & \\
\hline
\end{tabular}

Abbreviation: PSCl, post-stroke cognitive impairment; BMI, body mass index; NIHSS, National Institute of Health Stroke Scale; MoCA, Montreal Cognitive Assessment; $A \beta$, amyloid beta; p-tau181, phosphorylated tau 181; BDNF, Brain-derived neurotrophic factor; IQR, interquartile range; $S D$, standard deviation.

Table 2. Univariate and multivariate logistic regression analyses for patients with PSCl and without PSCl at 3 months and 12 months, respectively 


\begin{tabular}{|c|c|c|c|c|c|c|c|c|}
\hline & 3 months & & & & 12 months & & & \\
\hline Variables & OR(95\%Cl) & $\begin{array}{l}\mathrm{p}- \\
\text { value }\end{array}$ & $\mathrm{OR}^{\mathrm{a}}(95 \% \mathrm{Cl})$ & $\begin{array}{l}\mathrm{p}- \\
\text { value }\end{array}$ & OR(95\%Cl) & $\begin{array}{l}\mathrm{p}- \\
\text { value }\end{array}$ & $\mathrm{OR}^{\mathrm{a}}(95 \% \mathrm{Cl})$ & $\begin{array}{l}\mathrm{p}- \\
\text { value }\end{array}$ \\
\hline AGE & $\begin{array}{l}1.02(0.99- \\
1.06)\end{array}$ & 0.1240 & & & $\begin{array}{l}1.03(1.00- \\
1.06)\end{array}$ & 0.0261 & & \\
\hline Male & $\begin{array}{l}1.30(0.56- \\
3.00)\end{array}$ & 0.5412 & & & $\begin{array}{l}0.90(0.42- \\
1.94)\end{array}$ & 0.7947 & & \\
\hline Education $>9$ & $\begin{array}{l}0.44(0.21- \\
0.93)\end{array}$ & 0.0312 & $\begin{array}{l}0.27(0.09- \\
0.81)\end{array}$ & 0.0191 & $\begin{array}{l}0.51(0.25- \\
1.04)\end{array}$ & 0.0645 & & \\
\hline Hypertension & $\begin{array}{l}3.00(0.97- \\
9.30)\end{array}$ & 0.0571 & $\begin{array}{l}8.39(1.44- \\
48.90)\end{array}$ & 0.0181 & $\begin{array}{l}0.87(0.37- \\
2.05)\end{array}$ & 0.7563 & & \\
\hline Diabetes mellitus & $\begin{array}{l}1.33(0.62- \\
2.86)\end{array}$ & 0.4592 & & & $\begin{array}{l}1.58(0.76- \\
3.26)\end{array}$ & 0.2135 & & \\
\hline Dyslipidemia & $\begin{array}{l}1.15(0.48- \\
2.75)\end{array}$ & 0.7568 & & & $\begin{array}{l}1.02(0.45- \\
2.31)\end{array}$ & 0.9563 & & \\
\hline Smoking & $\begin{array}{l}1.78(0.83- \\
3.78)\end{array}$ & 0.1368 & & & $\begin{array}{l}1.52(0.74- \\
3.09)\end{array}$ & 0.2481 & & \\
\hline Drinking & $\begin{array}{l}0.85(0.25- \\
2.84)\end{array}$ & 0.7900 & & & $\begin{array}{l}0.40(0.11- \\
1.50)\end{array}$ & 0.1754 & & \\
\hline NIHSS $\leq 7$ days & $\begin{array}{l}1.01(0.91- \\
1.11)\end{array}$ & 0.9176 & & & $\begin{array}{l}1.01(0.92- \\
1.10)\end{array}$ & 0.9206 & & \\
\hline \multicolumn{9}{|l|}{$\begin{array}{l}\text { Plasma biomarkers at } \\
\text { baseline }\end{array}$} \\
\hline Tau, pg/mL & $\begin{array}{l}0.97(0.92- \\
1.01)\end{array}$ & 0.1737 & & & $\begin{array}{l}1.00(0.96- \\
1.04)\end{array}$ & 0.9822 & & \\
\hline $\mathrm{A} \beta 42, \mathrm{pg} / \mathrm{mL}$ & $\begin{array}{l}0.98(0.83- \\
1.16)\end{array}$ & 0.7846 & & & $\begin{array}{l}1.05(0.90- \\
1.23)\end{array}$ & 0.5597 & & \\
\hline $\mathrm{A} \beta 40, \mathrm{pg} / \mathrm{mL}$ & $\begin{array}{l}1.01(0.93- \\
1.10)\end{array}$ & 0.7445 & & & $\begin{array}{l}1.07(0.98- \\
1.17)\end{array}$ & 0.1458 & & \\
\hline $\mathrm{p}$-tau181, pg/mL & $\begin{array}{l}0.63(0.43- \\
0.91)\end{array}$ & 0.0151 & $\begin{array}{l}0.62(0.40- \\
0.94)\end{array}$ & 0.0243 & $\begin{array}{l}0.72(0.51- \\
1.02)\end{array}$ & 0.0640 & $\begin{array}{l}0.69(0.47- \\
0.99)\end{array}$ & 0.0443 \\
\hline BDNF, pg/mL & $\begin{array}{l}1.00(1.00- \\
1.00)\end{array}$ & 0.6768 & & & $\begin{array}{l}1.00(1.00- \\
1.00)\end{array}$ & 0.1198 & & \\
\hline \multicolumn{9}{|l|}{ Fazekas scale } \\
\hline $\begin{array}{l}\text { Periventricular white } \\
\text { matter }\end{array}$ & $\begin{array}{l}1.66(1.20- \\
2.31)\end{array}$ & 0.0024 & & & $\begin{array}{l}1.45(1.07- \\
1.97)\end{array}$ & 0.0154 & & \\
\hline Deep white matter lesion & $\begin{array}{l}1.44(0.99- \\
2.10)\end{array}$ & 0.0547 & & & $\begin{array}{l}1.09(0.77- \\
1.55)\end{array}$ & 0.6323 & & \\
\hline \multicolumn{9}{|l|}{$\begin{array}{l}\text { Mirobleed anatominal } \\
\text { rating scale }\end{array}$} \\
\hline Intratentorial score & $\begin{array}{l}1.43(0.95- \\
2.15)\end{array}$ & 0.0832 & & & $\begin{array}{l}1.49(0.94- \\
2.36)\end{array}$ & 0.0916 & & \\
\hline Deep score & $\begin{array}{l}1.42(0.99- \\
2.03)\end{array}$ & 0.0549 & & & $\begin{array}{l}1.31(0.94- \\
1.82)\end{array}$ & 0.1109 & & \\
\hline Lobar score & $\begin{array}{l}1.60(1.08- \\
2.37)\end{array}$ & 0.0190 & & & $\begin{array}{l}1.34(0.97- \\
1.86)\end{array}$ & 0.0791 & & \\
\hline
\end{tabular}

a: multiple logistic regression model using the automatic forward selection 
Abbreviation: PSCl, post-stroke cognitive impairment; NIHSS, National Institute of Health Stroke Scale; Aß, amyloid beta; p-tau181, phosphorylated tau 181; BDNF, Brain-derived neurotrophic factor

Table 3. Discrimination and reclassification statistics of p-tau181 level for patients with $\mathrm{PSCl}$ at 3 months and 12 months, respectively

\begin{tabular}{|c|c|c|c|c|c|c|c|}
\hline \multirow{2}{*}{$\begin{array}{l}\text { Clinical } \\
\text { outcomes }\end{array}$} & \multirow[t]{2}{*}{ Model } & \multicolumn{3}{|l|}{ NRI index } & \multicolumn{3}{|l|}{ IDI index } \\
\hline & & Estimate & $95 \% \mathrm{Cl}$ & $\begin{array}{l}\text { p- } \\
\text { value }\end{array}$ & Estimate & $95 \% \mathrm{Cl}$ & p-value \\
\hline \multirow{3}{*}{$\begin{array}{l}\mathrm{PSCl} \text { at } 3 \\
\text { month }\end{array}$} & Conventional model & & & & & & \\
\hline & Conventional model + image biomarker & 0.369 & $\begin{array}{l}(0.002- \\
0.735)\end{array}$ & 0.0522 & 0.035 & $\begin{array}{l}(0.004- \\
0.067)\end{array}$ & 0.0289 \\
\hline & $\begin{array}{l}\text { Conventional model + image biomarker } \\
+p \text {-tau181 level }\end{array}$ & 0.786 & $\begin{array}{l}(0.417- \\
1.155)\end{array}$ & 0.0010 & 0.144 & $\begin{array}{l}(0.074- \\
0.214)\end{array}$ & $<0.0001$ \\
\hline \multirow{3}{*}{$\begin{array}{l}\mathrm{PSCl} \text { at } 12 \\
\text { months }\end{array}$} & Conventional model & & & & & & \\
\hline & Conventional model + image biomarker & 0.235 & $\begin{array}{l}(-0.111- \\
0.582)\end{array}$ & 0.1884 & 0.016 & $\begin{array}{l}(-0.002- \\
0.034)\end{array}$ & 0.0890 \\
\hline & $\begin{array}{l}\text { Conventional model + image biomarker } \\
\text { +p-tau181 level }\end{array}$ & 0.730 & $\begin{array}{l}(0.326- \\
1.134)\end{array}$ & 0.0023 & 0.086 & $\begin{array}{l}(0.028- \\
0.145)\end{array}$ & 0.0040 \\
\hline
\end{tabular}

Conventional risk factors included age, gender, education, hypertension, diabetes mellitus, and NIHSS $\leq 7$ days

Abbreviation: PSCl, post-stroke cognitive impairment; NRI, net reclassification index; IDI, integrated discrimination improvement; $\mathrm{p}$ tau181, phosphorylated tau 181

Table 4. Association between plasma biomarkers and different persistent cognitive impairment status according to CDR-SB at 3 months and 12 months

\begin{tabular}{|c|c|c|c|c|c|c|c|c|c|}
\hline \multirow{2}{*}{$\begin{array}{l}\text { Plasma biomarkers } \\
\text { Aß 42, } \\
\text { pg/mL, median(IQR) }\end{array}$} & \multicolumn{2}{|c|}{$\begin{array}{l}\text { Persistent Non- } \\
\text { PSCl }(n=69)\end{array}$} & \multicolumn{2}{|c|}{$\begin{array}{l}\text { Delayed-onset } \\
\operatorname{PSCl}(n=27)\end{array}$} & \multicolumn{2}{|c|}{$\begin{array}{l}\text { Early PSCI with } \\
\text { reversal }(n=17)\end{array}$} & \multicolumn{2}{|c|}{$\begin{array}{l}\text { Persistent PSCI } \\
(n=23)\end{array}$} & \multirow{2}{*}{$\begin{array}{l}\text { p- } \\
\text { value } \\
0.7145\end{array}$} \\
\hline & 15.65 & $(3.26)$ & 16.04 & $(3.86)$ & 15.84 & $(2.86)$ & 15.40 & $(2.29)$ & \\
\hline $\begin{array}{l}\mathrm{A} \beta \text { 40, } \\
\mathrm{pg} / \mathrm{mL}, \operatorname{median}(\mathrm{IQR})\end{array}$ & 49.58 & (7.03) & 49.99 & (8.68) & 48.22 & $(5.01)$ & 51.49 & $(8.75)$ & 0.1796 \\
\hline $\begin{array}{l}\mathrm{A} \beta \text { 42/40 ratio, } \\
\% \text {, median(IQR) }\end{array}$ & 0.35 & $(0.10)$ & 0.33 & $(0.11)$ & 0.33 & $(0.17)$ & 0.32 & $(0.12)$ & 0.2213 \\
\hline $\begin{array}{l}\text { Tau, } \\
\mathrm{pg} / \mathrm{mL}, \text { median(IQR) }\end{array}$ & 18.43 & (11.62) & 19.69 & (16.03) & 19.63 & (9.33) & 18.54 & (7.38) & 0.6076 \\
\hline $\begin{array}{l}\mathrm{p} \text {-tau181, pg/mL, } \\
\text { mean(SD) }\end{array}$ & 4.40 & $(1.77)$ & 3.65 & $(1.41)$ & 3.36 & (1.38) & 3.12 & $(0.78)$ & 0.0081 \\
\hline $\begin{array}{l}\text { BDNF, pg/mL, } \\
\text { median(IQR) }\end{array}$ & 776.52 & (359.35) & 639.77 & (378.88) & 750.62 & (261.49) & 729.74 & (402.71) & 0.9267 \\
\hline
\end{tabular}

Abbreviation: PSCl, post-stroke cognitive impairment; CDR-SB, Clinical Dementia Rating global score, Sum of Boxes; $A \beta$, amyloid beta; $p$ tau181, phosphorylated tau 181; BDNF, Brain-derived neurotrophic factor; IQR, interquartile range; SD, standard deviation. 


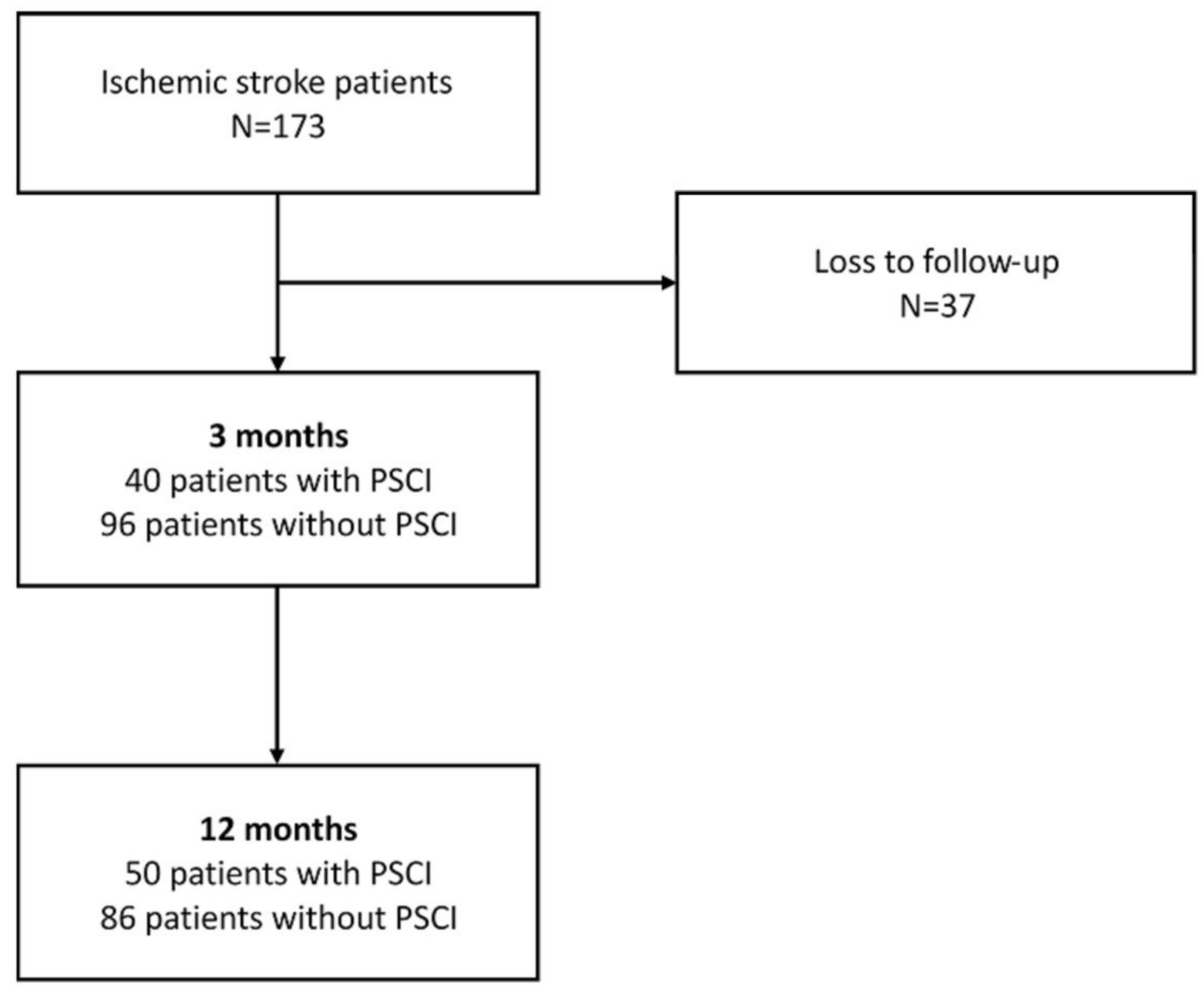

Figure 1

Flowchart of patient enrollment and cognitive function changes during the 12 months' follow-up. 
(A)

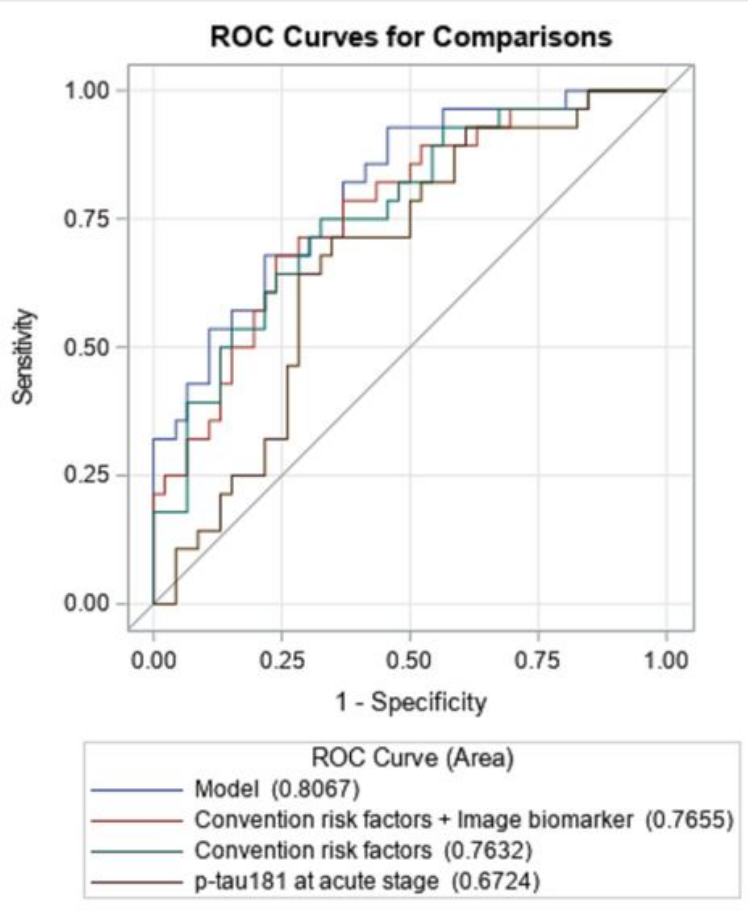

(B)

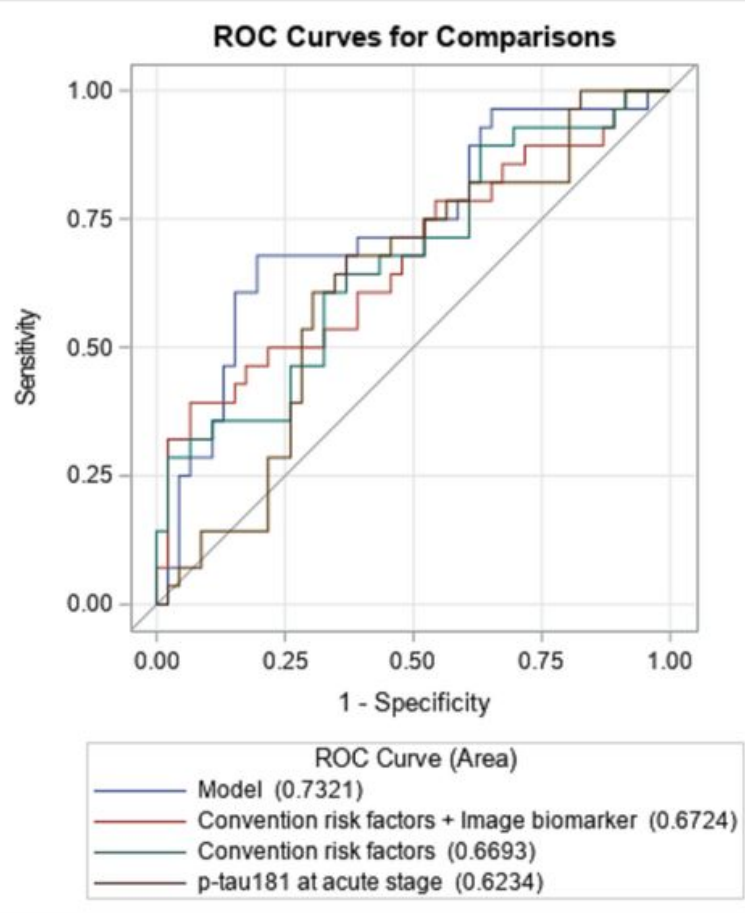

Figure 2

The area under the receiver operating characteristic of the ptau-181 predicting $\mathrm{PSCl}$ at $3(\mathrm{~A})$ and 12 months(B), respectively, when compared to conventional risk factors with image markers 